\title{
The use of social environment in a psychosocial clubhouse to facilitate recovery-oriented practice
}

\author{
Toby Raeburn, Virginia Schmied, Catherine Hungerford and Michelle Cleary
}

\section{Background}

Recovery-oriented language has been widely adopted in mental health policy; however, little is known about how recovery practices are implemented within individual services, such as psychosocial clubhouses.

\section{Aims}

To explore how recovery practices are implemented in a psychosocial clubhouse.

\section{Method}

Qualitative case study design informed by self-determination theory was utilised. This included $120 \mathrm{~h}$ of participant observation, interviews with 12 clubhouse members and 6 staff members. Field notes and interview transcripts were subject to theoretical thematic analysis.

\section{Results}

Two overarching themes were identified, each comprising three sub-themes. In this paper, the overarching theme of 'social environment' is discussed. It was characterised by the sub-themes, 'community and consistency', 'participation and opportunity' and 'respect and autonomy'.

\section{Conclusions}

Social environment was used to facilitate recovery-oriented practice within the clubhouse. Whether recovery is experienced by clubhouse members in wider society, may well depend on supports and opportunities outside the clubhouse.

\section{Declaration of interests}

None.

\section{Copyright and usage}

(C) The Royal College of Psychiatrists 2016. This is an open access article distributed under the terms of the Creative Commons Non-Commercial, No Derivatives (CC BY-NC-ND) licence.
Despite substantial advancements in clinical treatment, people with mental illness continue to endure poor social predicaments, including high rates of stigma, unemployment and homelessness. ${ }^{1-3}$ Such challenges highlight the importance of delivering mental healthcare that addresses both clinical and social needs. ${ }^{4}$ In response to consumer dissatisfaction with the traditional emphasis on symptoms and disability, mental health policy in many countries now promotes the concept of personal recovery. ${ }^{5,6}$

Personal recovery refers to a process of restoring mental health in accordance with a person's goals and strengths, enabling pursuit of a satisfying and contributing life, with or without the presence of continued symptoms. ${ }^{7}$ Interventions that promote personal recovery are commonly referred to as recovery-oriented practice. A broad range of services from both hospital and community sectors have adopted recovery-oriented practices, and the evaluation of such practices is a growing field of research. ${ }^{5,8-10}$

The personalised nature of mental health recovery has reinforced the apparent pragmatism of many individualised approaches to mental healthcare, such as individual psychotherapy and individualised employment support. ${ }^{11}$ In tandem with this, however, consumer accounts commonly emphasise the importance of social environments to their recovery. ${ }^{7}$ Social environments refer to the groups and neighbourhoods that people live in, the structure of workplaces and conventions that influence how people behave. ${ }^{12}$ One approach well known for its use of social environment and work to facilitate recovery is the clubhouse model of psychosocial rehabilitation.

The clubhouse model is widely recognised as a pioneer of recovery-oriented practice. ${ }^{13}$ Open to adults with a history of mental illness, there are over 300 clubhouses worldwide, including 8 in the UK. ${ }^{14}$ Referring to service participants as 'members', clubhouses place strong emphases on employment, social environment and recovery. ${ }^{15}$ For example, an unpaid vocational programme referred to as 'the work ordered day' involves members in daily activities, such as running a reception desk, working in a kitchen or clubhouse building maintenance. A transitional employment programme (TEP) offers paid semi-independent short-term job placements with local businesses, encouraging pursuit of independent paid employment. For members who have secured independent employment but still wish to receive support, there is also an ongoing clubhouse-supported employment programme. ${ }^{16}$

While most clubhouse studies have been carried out in North America, there is a growing body of research being conducted in clubhouses in other countries. For example, studies at clubhouses in South Korea ${ }^{17}$ and Hong Kong ${ }^{18}$ have found that participation in clubhouses improves quality of life and reduces psychiatric symptoms. Because the prerequisite for membership is a history of mental illness, clubhouses form a meeting place for people with similar experiences, facilitating supportive connections and friendships. ${ }^{15}$ Two other studies at clubhouses in Sweden ${ }^{19}$ and Australia ${ }^{20}$ have found that peer support within clubhouses can contribute to improved self-esteem, promoting mental health recovery.

This paper reports findings from a qualitative case study that explored how recovery-oriented practices were implemented within an Australian clubhouse. The study sought to address the following two questions: 'how are recovery practices perceived by members and staff within a psychosocial clubhouse?' and 'how are recovery practices embodied in the behaviour of staff?'

\section{Method}

\section{Design}

Qualitative case study design was selected because of the usefulness of the approach for elucidating phenomena within their natural setting. ${ }^{21}$ Similar to other qualitative designs, case studies draw on the data from multiple perspectives - however, they are not bound by a particular theoretical paradigm, instead allowing research to be informed by whatever theory is relevant to the case. ${ }^{21}$ This case study was informed by a modern theory well suited to recoveryoriented practice research, known as self-determination theory $(\mathrm{SDT}) .{ }^{22}$ 


\section{Theoretical framework}

A meta-theory of human motivation, SDT posits that humanity has three fundamental psychological needs: relatedness, competency and autonomy, and that the fulfilment of these needs can be influenced by social environments. ${ }^{22}$ 'Relatedness' refers to people's need for supportive relationships. 'Competence' describes people's desire to feel a sense of contribution in their community. 'Autonomy' denotes the importance of freedom and choice. ${ }^{22}$ Each of these needs is integral to the modern concept of recoveryoriented practice implemented within services such as psychosocial clubhouses. $^{23}$

\section{Setting}

The setting was an Australian psychosocial clubhouse, which is fully accredited with the International Clubhouse Standards, as disseminated by the original psychosocial clubhouse, known as Fountain House, in New York City. Housed in an open-plan building, the clubhouse provides programmes to 20-60 people per day. Following the timetable of a typical 5-day working week, activities are delivered from 09:00 h to 17:00 h, Monday-Friday, with occasional social outings on evenings and weekends. All activities are free of charge and open to adults over the age of 18 with a history of mental illness. Funding is drawn from a variety of government grants and philanthropic donations.

\section{Ethics}

The first author (T.R.) liaised closely with the clubhouse director, staff and members, in order to ensure that all research activity was aligned with clubhouse expectations of member involvement. ${ }^{24}$ Institutional consent for the study was secured from the clubhouse, and approval was granted by a university ethics committee in 2014 (H10711)

\section{Participants and recruitment}

All data were collected by T.R. between November 2014 through to and including January 2015. The study aimed to recruit a sample of 10 members for interviews and 5 staff members for participant observation and interviews. The study was promoted through notice-board advertisements and word of mouth among members to recruit interview volunteers, and among staff, to recruit for both participant observation and interviews. All participants were provided with ethics-approved information sheets, with completed signed consent required prior to involvement.

Participant observation focused on how six clubhouse staff members implemented recovery practices and was guided by two fieldwork tools, Spradley's field note domains, ${ }^{25}$ and the Recovery and Promotion Fidelity Scale (RPFS). ${ }^{26}$ Spradley ${ }^{25}$ suggests field notes should reflect nine domains, these are outlined in Table 1. Field notes were recorded in relation to each domain, with reference to the way in which staff embodied the recovery categories of the RPFS. ${ }^{26}$ The RPFS provides an empirically validated instrument for investigating the recovery orientation of mental health services. ${ }^{27}$ It divides recovery practices into five potential categories: collaboration; participation and acceptance; self-determination and peer support; quality improvement; consumer and staff development. ${ }^{26}$

Interviews with member and staff participants took place in a private room in the clubhouse, using questions from the RPFS, ${ }^{26}$ which reflected the five recovery categories mentioned above. The questions addressed topics including but not limited to, member involvement in the clubhouse, how feedback from members and staff occurred, members' goals within the clubhouse and how recovery principles were promoted. Interviews were digitally recorded, transcribed and coded, so that participant confidentiality was maintained. ${ }^{28}$

\section{Data analysis}

Collected data were subjected to theoretical thematic analysis. ${ }^{29}$ This meant searching for patterns within the data relevant to the research questions and principles of SDT, including relatedness, competency and autonomy. Analyses followed the six-step process suggested by Braun \& Clarke. ${ }^{29}$

The first step involved immersion in the collected data to build familiarity with its meaning, this was achieved by reading and rereading field notes and interview transcripts. Second, initial codes were developed, which involved splitting the data into pieces (phrases and paragraphs) that communicated particular messages related to the research questions, in light of SDT. For example, as noted in the Results section below, one member stated:

In other services that I've been along to, there seems to be much more of a divide between staff - often there'd be uniforms or... desks and the person sits on one side.... (while here) it's very open and everyone's sitting around together. (m11W)

This statement was coded as relevant to the research questions and SDT, because it conveyed a member perspective about the sense of relatedness in the clubhouse. ${ }^{30}$ Third, similar coded pieces of data were grouped together into themes. Fourth, the themes were refined and two overarching themes were developed, with three sub-themes in each. Fifth, points of interest about the themes were identified and linked together. Finally, a story about the data was produced.

\section{Rigour}

In relation to the credibility or authenticity of this qualitative study, ${ }^{31}$ the words of participants were used in the description of findings as much as possible, to strengthen credibility. Adopting SDT as a theoretical framework, and the RPFS for recovery categories and interview questions, also improved credibility. This is because SDT has been widely researched ${ }^{22}$ and the RPFS has been empirically validated. ${ }^{26,27}$ Throughout data collection and

\begin{tabular}{|c|c|}
\hline Space & Locations where observations were recorded. For example, in the art room or cafeteria of the clubhouse. \\
\hline Actors & Staff observed and number of members. For example, staff $X$ and staff $Y$ worked with a group of ten members. \\
\hline Activity & Events that the actors (staff and members) engaged in. For example, a lunch-time cooking group. \\
\hline Object & Physical artefacts present during an activity. For example, food ingredients, stove and other kitchen utensils. \\
\hline Act & $\begin{array}{l}\text { Individual behaviours that actors engaged in during an activity. For example, how a staff member used a whiteboard to facilitate task allocation } \\
\text { during a cooking group. }\end{array}$ \\
\hline Event & Summary title for groups of activities. For example, a fundraising day. \\
\hline Time & Times when periods of observation took place. \\
\hline Goal & The apparent intention of actors during activities. For example, staff sought to involve members in food preparation as much as possible. \\
\hline Feeling & $\begin{array}{l}\text { Emotions conveyed by actors during activities. For example, staff appeared happy when several members volunteered to contribute to the } \\
\text { fundraising day activity. }\end{array}$ \\
\hline
\end{tabular}


analyses, T.R. engaged in regular reviews and discussions with the co-authors, who are all highly experienced qualitative researchers. This approach enhanced reflexivity throughout the study. ${ }^{32}$

Two overarching themes were developed: 'social environment' and 'autonomy support'. The overarching theme of 'autonomy support' is explored in a separate publication. ${ }^{33}$ The current paper addresses sub-themes related to the first overarching theme of 'social environment'.

\section{Results}

\section{Participants}

Research participants were 12 clubhouse members and 6 staff members; all study data came entirely from this cohort. Member participants included eight males and four females, with an average age of 47 years; all reported a diagnosis of either schizophrenia, bipolar disorder or schizoaffective disorder; each had been attending the clubhouse for between 1 and 20 years. Staff participants included two males and four females, with an average age of 39. Each had been working at the clubhouse for between 1 and 7 years and had professional qualifications (e.g. occupational therapy, art therapy and social work).

\section{Themes}

The three sub-themes that related to social environment were 'community and consistency', 'participation and opportunity' and 'respect and autonomy'. Each of these themes will now be discussed in turn, with direct quotes from field notes prefaced with the prefix 'fn', interview quotes from members with the prefix ' $m$ ' and interview quotes from staff members with the prefix 's'.

\section{Community and consistency}

Staff members described the social environment at the clubhouse as being a community that sought to support each member's personal recovery journey. This was described by staff with comments such as:

We are a community before we are a service. The critical thing for us is to provide a safe and welcoming environment where members... can come in, belong to and take part in. (s3C)

Likewise, members compared the inclusive, community feel of the social environment to their experiences with other services. For example:

In other services that I've been along to, there seems to be much more of a divide between staff - often there'd be uniforms or... desks and the person sits on one side.... (while here) it's very open and everyone's sitting around together. (m11W)

This sense of community-reflected principles is outlined in the 36 guiding principles of the organisation, known as the International Clubhouse Standards. ${ }^{34}$ These standards were displayed at reception and in various other places throughout the building, outlining the purpose of the organisation, the rights of members and providing guidance for daily activities. The sense of community at the clubhouse, then, was sustained through the relational routines crafted to reflect these standards. One such routine was described in the following field note:

Every day begins with a morning meeting of staff and members where a clubhouse standard is read aloud. A reflection and debate between members and staff then follows about the relevance of the standard to mental health recovery. (fn5N)

The standards, together with the routine connected to this reading of the standards, provided an important means of building and supporting the community.

There was also debate however, among members and staff, about the cultural tone of the standards and whether they should allow more scope for local innovation. These concerns were exemplified by comments such as:
The clubhouse model was developed so long ago. We feel there is need for it to evolve. Obviously when the accreditors came they were extremely work focused, but their culture is American, which is obviously very different - in Australia it's completely different. So I think it's important for that to be realised. But everybody has said it takes a very long time for the clubhouse standards to change. (s2X)

Concerns about how the standards were implemented had been highlighted during the clubhouse's most recent accreditation process. Staff stated:

The accreditor didn't see the benefit of members going for a walk around lunchtime. He felt that it distracted from the work order day. But we made the point that in workplaces people can exercise, and I think if you're given those options, you become more motivated with your work. (S3Y)

Although there were concerns about how concretely the standards influenced practice, the theme of community was further supported by the fact that the only criterion to access the clubhouse was a history of mental illness. Guaranteed acceptance by the clubhouse was highly valued by members, who made comments during interviews such as:

I was alienated from my family. I lost my support system. I lost my job. I couldn't pay my mortgage. I had debts... The clubhouse was the only support system left when everything (was gone)....it's been very... welcoming. (m6S)

Furthermore, notions of community and consistency continued to be extended to members on a lifelong basis, no matter how many times they needed to access the service:

I think the beauty of this model is that because it's open, you know you're a member for life, you can transition on as many times as you want. People will transition through and then we won't see them for a couple of years and then they'll have an episode and be back in hospital and then they'll transition out again through us. (s6N)

The episodic nature of mental illness, and the fact that recovery is seldom a linear process, meant member's reputation in their family and friendship groups was often vulnerable. Community and consistency at the clubhouse facilitated an accepting social environment that members could rely on - thereby addressing their feelings of vulnerability.

\section{Participation and opportunity}

Another important component of the social environment was the opportunity for members to develop a sense of competency through participation in work. Members valued the chance to build confidence and skills through involvement in a range of vocational activities. This was illustrated by quotes from interviews such as:

The clubhouse's goal is to work. In the sense of - what you decide work is. Is work keeping well? Is work having a hobby or developing a business? Is work going in and working in a kitchen? (m1R)

Although voluntary and unpaid, members perceived the vocational work activities as holding value other than money. This was reflected in comments such as:

Within the structure of the clubhouse you've got your daily work...(which) teaches skills for one... (I) had a lot of difficulty just shopping... but now I can do things. I'm a lot more able to do things independently as a result of my time... spent at clubhouse. (m12G)

Many work activities provided opportunities to engage in administrative duties. Some of these were recorded in the field note below:

Members engage in a wide range of business related activity groups performing secretarial/reception duties, writing grant applications and the weekly newsletter. They also publish and fold pamphlets for community groups and organize health promotion and fundraising events. (fnD5)

Other opportunities to participate included horticultural work maintaining the clubhouse's outdoor gardens. There was also a range of artistic activities for members with creative interests, as noted below:

I like the activities they have on like the art group and the art deco and the writer's group and the drama group. I like to get involved. It helps me get skills. (m5R)

While members generally enjoyed the participation and opportunities on offer, however, there are times that this seemed to engender such comfort within the clubhouse, that some members 
lost motivation to pursue opportunities in wider society. This observation was reflected in the following statement by staff:

Sometimes you'll have people that you're working with and it's actually quite short term because you sort of can facilitate a lot of stuff and then they move on. It's a little more difficult with people I think who have been coming here for the last ten years. That can get a bit more blurry as to what it is you're trying to facilitate other than just being sort of a social club. (s3Z)

Despite this, vocational programmes inside the clubhouse were connected to transitional employment support for members seeking paid employment outside, in the competitive job market. The way this process worked was explained in the following vignette provided by a staff member:

.you're giving very practical tasks and showing them how to do them where there is no sense of failure and then giving them that encouragement that they can do it.. I had a man .... with extremely high anxiety who... would just sit at the back of the dining room and not talk to anyone at all. I helped him work in the kitchen and then he did one of those transitional employment positions... where they fulfil manual tasks.. That gave him the courage to do a hospitality course... while he was doing it he said 'I need to learn a bit more cooking', so he was coming back to the kitchen to cook once or twice a week. Then he got a job at the kiosk at the hospital and he's been there now two and a half years. Now he told me about six months ago he became a team leader. (S1C)

Step-by-step, then, members were supported to gain confidence and skills, building a sense of competency in relation to the contribution they could make to the clubhouse and their wider community.

\section{Respect and autonomy}

The theme of 'respect and autonomy' was observed in the way staff members encouraged respectful communication and behaviour among members. A relaxed approach to how members used the service was adopted, meaning that while work activities were consistent, and participation was encouraged, staff members did not force members to get involved. Such autonomy was appreciated by members who made comments such as:

I'm allowed to work wherever I want, whenever I want, yep. That's what this clubhouse is all about. Choice, yep. You have as much choice as you like. (m3G)

In a similar vein, members appreciated the way staff members respected their right to opt out of activities when they wanted to. This was reflected in statements such as:

I like how you can say no if they ask you to help to work... - it's voluntary, you should be able to say no at any time. (m10S)

Occasionally, however, promotion of autonomy needed to be tempered by staff - particularly when individual members began to speak or act in unsociable ways. Staff members were observed encouraging polite verbal interaction in a gentle but firm way to maintain a safe social environment. This is highlighted in the following comment made by staff:

they can't help it if they hear voices and respond to voices every so often. But if they swear... because they do, that's just not on... I just try to catch it and encourage polite behavior (s3C)

At the same time, staff members were occasionally required to monitor access to the service; this was exemplified in the following vignette of an incident observed during participant observation:

An inebriated man carrying several bags over his shoulder and a bottle of alcohol in his hand entered the clubhouse and strode over to a computer station swearing under his breath. Members working nearby appeared startled by the interruption, dropping their heads and falling silent. A staff member was quick to sense the effect of the man's behavior and politely asked him to leave. The man replied he had meeting scheduled for midday. The staff member then explained and reinforced that the clubhouse was supposed to be a safe place to work and socialize, negotiating fo the man to return later in the day for his meeting. (fnD7)

Perhaps the importance of respect and autonomy was best summed up by a member's statement below:

After hospitalization, if you've had an episode, trusting yourself is something you need, to rebuild again with confidence, and coming to the clubhouse there is automatic trus in the sense that people feel safe and staff treat you with respect' (m1R)

The respect and autonomy facilitated by the social environment at the clubhouse engendered feelings of safety, trust and confidence. By building such feelings, members could continue developing a sense of self-determination and personal recovery.

\section{Discussion}

This study revealed three sub-themes that suggested social environment was instrumental to the way in which recovery practices were implemented within a clubhouse. The first subtheme, 'community and consistency', was conveyed by member and staff descriptions of the clubhouse social environment, as exceeding everyday notions of 'service provision'. The sense of community and consistency within the clubhouse was built on a set of values and social routines crafted to reflect the International Clubhouse Standards. ${ }^{34}$ Because it provided a standardised approach and attendance was voluntary, the clubhouse tended to attract people amenable to its values. The longer members and staff had spent within the clubhouse, the more familiar they appeared to be with the language of the standards, and this influenced how they interacted.

In some respects, the notion of drawing people into a mental health community evoked imagery of traditional institutional approaches and ran contrary to more contemporary communitybased services, which provide programmes focused on supporting people to integrate back into wider society. Despite this, Mandiberg $\&$ Warner ${ }^{14}$ contend that the intransigent social challenges faced by people with mental illness throughout history legitimise approaches such as those used in clubhouses. They argue that because recovery is a process and not an outcome, people with mental illness require more than services alone, and becoming a member of a community can restore a sense of identity and belonging, which can contribute to recovery. ${ }^{14}$

While promoting community and consistency, use of the standards was open to critique, because they also appeared to constrain local innovation. Staff members expressed concern that the language of the standards, and the way in which they were interpreted during accreditation, maintained old-fashioned and enculturated ideas about how work should be conducted. They also reported that effecting any change to the language or tone of the standards would take a very long time because any changes required formal ratification by the central office of the international clubhouse movement. While service standards can be beneficial for promoting purpose within organisations, SDT research suggests that overly centralised requirements to adhere to standards can dampen levels of motivation and innovation. ${ }^{22}$ Despite such concerns, the standards did enable the recovery practice of quality assurance to be implemented, through the clubhouse accreditation process. This contrasted with concerns raised in other mental health research that recovery practices often lack standardisation, making evaluation difficult. ${ }^{8}$

The second theme, 'participation and opportunity', was important because clubhouse members, like many people with mental illness, reported having experienced stigma, unemployment and damage to their reputation, due to their mental illness. ${ }^{1}$ Importantly, daily work within the clubhouse was the responsibility not only of staff but also of members. This meant that working together, to keep the clubhouse functioning, automatically facilitated recovery practices, like collaboration and acceptance between members and staff.

Staff members were observed facilitating a range of unpaid vocational work activities, including but not limited to telephone reception duties, managing the clubhouse website, producing marketing and health promotion materials, horticultural work in the clubhouse garden and food preparation in the clubhouse cafe. Every job was effectively broken down into achievable, explainable tasks and allocated to members, according to their level of interest and confidence. Viewed through the theoretical lens provided by SDT, such activities, although unpaid, provided a range of 
opportunities, through which members could increase skills and confidence, thereby increasing a sense of competency.

Perhaps the strongest criticism of the clubhouse approach has come from research focused on models of supported employment, such as individual placement and support (IPS). ${ }^{11}$ Critics suggest that facilitating vocational work in comfortable social environments can slow people's re-entry to paid work in wider society. ${ }^{35}$ During this study, such concerns appeared valid within the clubhouse, where some members reported having participated in vocational activities for many years but were in no hurry to pursue paid employment.

Quantitative outcome research in other psychosocial services has viewed people who spend years in vocational programmes without moving on to paid employment, as struggling to recover. ${ }^{11,36}$ Such studies highlight the importance of how recovery is conceptualised by research. Quantitative studies generally assume an outcomes-focused approach that differentiates between social recovery, including employment and interpersonal outcomes, and complete recovery, focused on symptom reduction. ${ }^{5}$ Such research approaches contrast with the notion of personal recovery, which as mentioned above has been used to describe a process of restoring identity in the context of community. ${ }^{7,14}$

The final theme of 'respect and autonomy', referred to the trust and freedom, members were accorded within the clubhouse. Members stated that while engaging and persevering with work activities were encouraged, participation was not forced on them. They appreciated having the choice to join, or leave work groups as they wished, or to stop working, and socialise with other members when they wanted. Members reciprocated the respect they were shown by expressing respect for the staff and the rules of the clubhouse. While firm rules governing safe behaviour, such as zero tolerance for violence, were observed being enforced by staff, occasions when this was required appeared rare. The theme of respect and autonomy connected with SDT, which suggests that when people experience freedom to make their own choices, they respond by behaving in socially constructive ways and experience a more satisfying life. ${ }^{22}$

\section{Limitations}

This study involved a single clubhouse and fieldwork was conducted with a relatively small group of participants, suggesting that the participation may have appealed more to people with a higher rate of involvement in the clubhouse. While the study explored an accredited clubhouse, there is likely to be variation in international clubhouse settings depending on local socioeconomic and cultural circumstances. Information collected was also limited by using participant observation as a data collection technique. This was because data could only be collected in situations the researcher was physically present to observe. ${ }^{37}$

Given the wide array of terms used to describe recovery concepts in mental health literature, another limitation was the restriction of recovery categories to those identified by the RPFS. ${ }^{26}$ Also, because of time constraints follow-up interviews with participants were not conducted. Such a process may have provided extra data, and guarded against missing points participants viewed as important. ${ }^{31}$ In relation to SDT, larger multisite research, exploring its use in other contexts and research designs, may provide confirmation of its viability for guiding recovery-oriented research.

\section{Implications}

It is now common for mental health recovery to be conceptualised as a personal process requiring a broad range of supports. Delivering clinical treatment and addressing social determinants such as employment and housing are vital, however restoring people's sense of belonging and identity are also important. This case study sought to address how recovery practices were perceived by members and staff within a psychosocial clubhouse and how recovery practices were embodied in the behaviour of staff.

Self-determination theory provided a helpful theoretical framework for the research, guiding in-depth exploration of recoveryoriented practice. Utilising participant observation and interviews, the study revealed that recovery practices were implemented by using social environment to facilitate a sense of community, participation and respect. Whether recovery practices experienced by members within the clubhouse facilitate recovery in wider society may well depend on links with family, friends and employment opportunities, outside the clubhouse.

Toby Raeburn, RN, MA, Virginia Schmied, RN, RM, PhD, School of Nursing \& Midwifery, Western Sydney University, Sydney, NSW, Australia; Catherine Hungerford, RN, NP, PhD, FACMHN, School of Nursing, Midwifery, and Indigenous Health, Faculty of Science, Charles Sturt University, Bathurst, NSW, Australia; Michelle Cleary, RN, PhD, School of Health Sciences, University of Tasmania, Sydney, NSW, Australia

Correspondence: Toby Raeburn, School of Nursing \& Midwifery, Western Sydney University, Post; 88 Mallet Street, Camperdown NSW 2006, Sydney, NSW, Australia. Email: 16473430@student.uws.edu.au

First received 20 Dec 2015, accepted 11 Mar 2016

\section{References}

1 Smith M. Anti-stigma campaigns: time to change. Br J Psychiatry 2013; 202 (suppl 55): s49-50.

2 Baggett TP, O'Connell JJ, Singer DE, Rigotti NA. The unmet health care needs of homeless adults: a national study. Am J Public Health 2010; 100: 1326-33.

3 Harvey SB, Modini M, Christensen $\mathrm{H}$, Glozier N. Severe mental illness and work: what can we do to maximise the employment opportunities for individuals with psychosis? Aust N Z J Psychiatry 2013; 47: 421-4.

4 Tew J, Ramon S, Slade M, Bird V, Melton J, Le Boutillier C. Social factors and recovery from mental health difficulties: a review of the evidence. Br J Soc Work 2012; 42: 443-60.

5 Slade $\mathrm{M}$, Leamy $\mathrm{M}$, Bacon $\mathrm{F}$, Janosik $\mathrm{M}$, Le Boutillier C, Williams J, et al. International differences in understanding recovery: systematic review. Epidemiol Psychiatr Sci 2012; 21: 353-64.

6 Tondora J, Miller R, Slade M, Davidson L. Partnering for Recovery in Mental Health: A Practical Guide to Person-Centered Planning. Wiley, 2014

7 Leamy M, Bird V, Le Boutillier C, Williams J, Slade M. Conceptual framework for personal recovery in mental health: systematic review and narrative synthesis. Br J Psychiatry 2011; 199: 445-52.

8 Hungerford C. Recovery as a model of care? Insights from an Australian case study. Issues Ment Health Nurs 2014; 35: 156-64.

9 Slade M, Bird V, Clarke E, Le Boutillier C, Mccrone P, Macpherson R, et al. Supporting recovery in patients with psychosis through care by community-based adult mental health teams (REFOCUS): a multisite, cluster, randomised, controlled trial. Lancet Psychiatry 2015; 2: 503-14.

10 Macpherson R, Pesola F, Leamy M, Bird V, Le Boutillier C, Williams J, et al. The Relationship between Clinical and Recovery Dimensions of Outcome in Mental Health. Schizophrenia Research, 2015.

11 Drake R, Bond G, Becker D. Individual Placement and Support: An Evidence-Based Approach to Supported Employment. Oxford University Press, 2012.

12 Yen $I H$, Syme SL. The social environment and health: a discussion of the epidemiologic literature. Annu Rev Public Health 1999; 20: 287-308.

13 Dudek KJ, Aquila R. Fountain house and recovery centers. Psychiatr Serv 2012; 63: 396

14 Mandiberg JM, Warner R. Is mainstreaming always the answer? The social and economic development of service user communities. Psychiatrist 2013; 37: 153-5.

15 Pernice-Duca F, Onaga E. Examining the contribution of social network support to the recovery process among clubhouse members. Am J Psychiatr Rehabil 2009; 12: $1-30$.

16 Raeburn T, Halcomb E, Walter G, Cleary M. An overview of the clubhouse model of psychiatric rehabilitation. Australas Psychiatry 2013; 21: 376-8. 
17 Jung SH, Kim HJ. Perceived stigma and quality of life of individuals diagnosed with schizophrenia and receiving psychiatric rehabilitation services: a comparison between the clubhouse model and a rehabilitation skills training model in South Korea. Psychiatr Rehabil J 2012; 35: 460-5.

18 Tsang AWK, Ng RMK, Yip KC. A six-month prospective case-controlled study of the effects of the clubhouse rehabilitation model on chinese patients with chronic schizophrenia. East Asian Arch Psychiatry 2010; 20: 23-30.

19 Schon U-K. The power of identification: peer support in recovery from mental illness. Scand J Disabil Res 2010; 12: 83-90.

20 Coniglio FD, Hancock N, Ellis A. Peer support within clubhouse: a grounded theory study. Community Ment Health J 2010; 48: 153-60.

21 Stake RE. The Art of Case Study Research. Sage, 1995.

22 Deci E, Ryan R. Overview of Self-Determination Theory. Oxford University Press, 2012.

23 Raeburn T, Schmied V, Hungerford C, Cleary M. Self-determination theory: a framework for clubhouse psychosocial rehabilitation research. Issues Ment Health Nurs 2015; 36: 145-51.

24 Horsfall J, Cleary M, Walter G, Hunt GE. Conducting mental health research: key steps, practicalities, and issues for the early career researcher. Int J Ment Health Nurs 2007; 16 (suppl 1): S1-20.

25 Spradley J. Participant Observation. Holt Rinehart and Winston, 1980

26 Armstrong N, Steffen J. The recovery promotion fidelity scale: assessing the organizational promotion of recovery. Community Ment Health J 2009; 45: 163-70.

27 Burgess $\mathrm{P}$, Pirkis J, Coombs T, Rosen A. Assessing the value of existing recovery measures for routine use in Australian mental health services. Aust $N Z$ J Psychiatry 2011; 45: 267-80.
28 Yin R. Case Study Research: Design and Methods. 4th edn. Sage, 2009

29 Braun V, Clarke V. Using thematic analysis in psychology. Qual Res Psychol 2006; 3: 77-101.

30 Mancini A. Self-determination theory: a framework for the recovery paradigm. Adv Psychiatr Treat 2008; 14: 358-65.

31 Thomas E, Magilvy JK. Qualitative rigor or research validity in qualitative research. J Spec Pediatr Nurs 2011; 16: 151-5.

32 Dowling M. Approaches to reflexivity in qualitative research. Nurse Res 2006; 13 7-21.

33 Raeburn T, Schmied V, Hungerford C, Cleary M. Autonomy support and recovery practice at a psychosocial clubhouse. Perspect Psychiatr Care. 27 Jan 2016 (epub ahead of print)

34 Macias C, Barreira P, Alden M, Boyd J. The ICCD benchmarks for clubhouses: a practical approach to quality improvement in psychiatric rehabilitation. Psychiatr Serv 2001; 52: 207-15.

35 Ritsner MS. Handbook of Schizophrenia Spectrum Disorders, Volume III. Therapeutic Approaches, Comorbidity, and Outcomes. Springer, 2011.

36 Lim C, Barrio C, Hernandez M, Barragán A, Brekke JS. Recovery from schizophrenia in community-based psychosocial rehabilitation settings rates and predictors. Res Soc Work Pract 2015; 1: 1-14.

37 schneider Z. Nursing Research: Methods, Critical Appraisal and Utilisation. Mosby Publishers, 2002 